\title{
A framework for current public mental health care practice in South Africa
}

\author{
ABR Janse Van Rensburg \\ Division of Psychiatry, Faculty of Health Sciences, University of the Witwatersrand, Johannesburg, South Africa
}

\begin{abstract}
One of the main aims of the new Mental Health Care Act, Act No. 17 of 2002 (MHCA) is to promote the human rights of people with mental disabilities in South Africa. However, the upholding of these rights seems to be subject to the availability of resources. Chapter 2 of the MHCA clarifies the responsibility of the State to provide infrastructure and systems. Chapters 5, 6 and 7 of the Act define and regulate the different categories of mental health care users, clarify the procedures around these categories and spell out mental health practitioners' roles and responsibilities in this regard. Also according to the National Health Act No. 61 of 2003, the State remains the key role player in mental health care provision, being responsible for adequate mental health infrastructure and resource allocation. Due to "limited resources" practitioners however often work in environments where staff ratios may be fractional of what should be expected and in units of which the physical structure and security is totally inadequate. The interface between professional responsibility of clinical workers versus the inadequacy of clinical interventions resulting from infrastructure and staffing constraints needs to be defined. This paper considered recent legislation currently relevant to mental health care practice in order to delineate the legal, ethical and labour framework in which public sector mental health practitioners operate as state employees. These included the Mental Health Care Act, No. 17 of 2002; the National Health Act, No. 61 of 2003 and the proposed Traditional Health Practitioners Act, No. 35 of 2004 . Formal legal review of and advice on this legislation as it pertains to public sector mental health practitioners as state employees, is necessary and should form the basis of the principles and standards for care endorsed by organized mental health care practitioner groups such as the South African Society of Psychiatrists (SASOP).
\end{abstract}

Key words: South African health legislation; Professional and state responsibility; Human rights; Available resources.

Received: 12-02-2007

Accepted: 21-05-2007

\section{Introduction}

New South African mental health legislation was promulgated in 2002 and implemented in December 2004. The main thrust of this act, the Mental Health Care Act, No.17 of 2002, is to provide for the care, treatment and rehabilitation of persons who are mentally ill, to set out different procedures to be followed in the admission of such persons and to establish review boards in respect of every health establishment. The main aims of the act are to promote the human rights of people with mental disabilities, to improve mental health services through a primary health care approach, to emphasize community care and to protect the safety of the public.

While high expectations from public mental health practitioners existed for resources to follow the passing of the new law, no national or provincial capital interventions materialized subsequent to the Act's promulgation in most of the country's nine provinces. It became clear that the act was passed without due consideration of the financial implications of implementation. As a result, previous patterns of clinical practice and factors determining management decisions in the public sector services simply continued as before. Public mental health care practice continued to be dictated by inadequate nursing staff ratios and suboptimal or structurally inappropriate facilities. In Gauteng Province, as in most other provinces, no adjustments to existing state facilities or staffing occurred and decisions, for example, to admit users directly as involuntary users to the provincial referral psychiatric hospitals continued to be determined by the lack of a local general district or regional hospital's capacity to safely contain restless and aggressive users. The escalation of professional risk to state employed clinicians attached to acute units - such as 72-hour observation units - in general hospitals became more evident over time, especially resulting from poor nursing and security staff ratios and from facilities inadequate for the new extended range of 
services to be provided. Personal and professional liability remains a constant potential threat where standards of care cannot be met or maintained.

A trend that established itself since the passing of the new mental health legislation, mainly due to the extensive and costly physical and staffing requirements that private facilities must fulfil to be licensed for assisted or involuntary care, is that private practitioners and service providers have generally distanced themselves from categories of service provision other than "voluntary" users. While strict requirements were laid down for the private sector, no norms and standards for public facilities aligning the State's own services with the new legislation were adopted. At the same time, as a result of this limited private sector involvement, the bulk of assisted and involuntary users are now routinely routed through the already compromised acute units of general state hospitals as the first point of entry to the mental health care system. Questions emerged from these experiences, such as: "Will the securing of human rights as incorporated in legislation always be subjected to 'available resources'?" and "What are the legal and ethical distinctions between clinical responsibilities of practitioners as employees vis-à-vis the State's responsibility to provide infrastructure?"

In addition, another example of change in the environment in which mental health care must be provided, is the mainstreaming of traditional African health practice through the recently proposed legislation on traditional health practice. The extent to which mental health care elements feature in the proposed legal definition of traditional health practice, may even necessitate the consideration of whether the multidisciplinary mental health care team should actually be extended in order to include alternative or traditional practitioners as well, resulting in a still bigger demand on available mental health care resources. All of these represent a new legal, ethical and labour framework for public sector mental health care practice in particular.

The aim of this paper is to consider, in particular, the Mental Health Care Act, No. 17 of 2002 (MHCA), the recent National Health Act, No. 61 of 2003 (NHA) and the proposed Traditional Health Practitioners Act, No. 35 of 2004 (THPA), in the context of a larger body of legislation currently relevant to mental health care practice in South Africa. Specifially, to achieve greater clarity on the new framework in which public sector mental health practitioners, including state employed psychiatrists, are currently expected to function. Legislation regarded as relevant to current mental health care in South Africa ${ }^{1}$ is summarized in Table 1.

\section{FRAMEWORK FOR PUBLIC PRACTICE}

\section{Legal and organizational framework}

(i) Definitions - The MHCA defines a "mental health care practitioner" as a registered psychiatrist, medical practitioner, nursing professional, counseling or clinical psychologist and occupational therapist or social worker who has been trained to provide prescribed mental health care, treatment and rehabilitation. A "mental health care provider" is defined as a person providing mental health care services to mental health care users and includes mental health care practitioners. The recently promulgated NHA refers to categories of workers in more general terms as "health care providers", where a "health practitioner or provider" is a person providing health services in terms of any law e.g. the above mentioned Allied Professions, Health Professions, Nursing, Pharmacy, and Dental Technicians Acts. Although referred back for certain constitutional
TABLE 1. LEGISLATION RELEVANT TO CURRENT MENTAL HEALTH CARE PRACTICE IN SOUTH AFRICA

\section{GENERAL}

Constitution of the RSA, Act No. 108 of 1996

Criminal Procedure Act, No. 51 of 1977

Basic Conditions of Employment Act, No. 75 of 1997

Labour Relations Act, No. 66 of 1995

Promotion of Access to Information Act, No. 2 of 2000

Employment Equity Act, No. 55 of 1998

2. HEALTH AND MENTAL HEALTH

National Health Act, No. 61 of 2003

Mental Health Care Act, No. 17 of 2002

3. ETHICAL AND PROFESIONAL CONDUCT

Health Professions Act, No. 56 of 1974

Allied Health Professions Act, No. 63 of 1982

Nursing Act, No. 50 of 1978

Pharmacy Act, No. 53 of 1974

Dental Technicians Act, no 19 of 1979

Medical, Dental and Supplementary Health Services Professions Amendment Acts, No. 18 of 1995 and No. 89 of 1997

4. ALTERNATINE AND TRADITIONAL PRACTICE

Chiropractors, Homeopaths and Allied Health Service Professions

Amendment Acts, No. 40 of 1995 and No. 91 of 1997

(Proposed) Traditional Health Practitioners Act, No. 35 of 2004

adjustments, the proposed THPA recently became relevant to the mental health care scenario due to it's emphasis on mental health in the definition of traditional health practice. The act defines it as "the performance of a function, activity, process or service that includes the utilization of a traditional medicine or practice with the object: (a) to maintain or restore physical or mental health or function; (b) to diagnose, treat and prevent physical or mental illness; (c) to rehabilitate a person to resume normal functions and (d) to physically and mentally prepare a person for phase of life changes (puberty, adulthood, pregnancy, childbirth and death)". A traditional health practitioner is defined as a person registered according to the THPA, including traditional birth attendants and traditional surgeons, but excludes professional activities of somebody registered according to the Health Professions, Pharmacy, Nursing or the Dental Technicians Acts.

(ii) Human rights - The Bill of Rights included in Chapter 2 of the South African Constitution, specifies all the basic human rights and the areas in which it must prevail under the headings of dignity, human dignity, life, freedom and security, slavery, servitude and forced labour, privacy, freedom of religion, belief and opinion, freedom of expression, assembly, demonstration, picket and petition, association, political rights, citizenship, movement and residence, trade, occupation and profession, labour relations, environment; property, housing, health care, food, water, social security, children, education, language and culture, cultural, religious and linguistic communities, access to information, just administrative action, access to courts, and arrested, detained and accused persons. Section 36 of the Constitution explains certain conditions under which these rights may be limited considering: " (a) the nature of the rights; (b) the importance of the purpose of the limitation; (c) the nature and extent of the limitation; (d) The relation between the 
limitation and its purpose; and (e) less restrictive means to achieve its purpose." The MHCA in Chapter 3 outlines the human rights of mental health care users to be protected. This includes respect for users, protection of privacy, consent to care, access to treatment and rehabilitation services and admission to health establishments, no unfair discrimination, exploitation or abuse, determinations concerning mental health status, disclosure of information, limitation on intimate adult relationships under certain conditions, the right to representation, the discharge of reports and the knowledge of their rights.

(iii) Mental Health Care System and Infrastructure - Health services in South Africa are rendered in public and private contexts. In earlier policy documents such as the original white paper on health before parliament ${ }^{2}$, specific guidelines were included on mental health, e.g. that mental health must be provided as integrated with other health services on all levels. The NHA promulgated during 2006 provides for the overall national structure and functions for health care provision in terms of national, provincial and local government. The National Department of Health according to the NHA has the function to implement national policy and issue guidelines, to liaise and promote adherence to standards, to identify national health goals and priorities, to monitor progress and to promote community participation (Chapter 3). Provincial government's responsibility include the provision of specialized hospitals, the planning and managing of provincial health information systems, the planning, coordinating, monitoring and evaluating of the rendering of health services, as well as the providing of health services contemplated by specific provincial health service programs (Chapter 4). Chapter 5 provides for the establishment of a district health service. The roles and functions of health establishments (hospitals, clinics, etc) and their place within the national health system are addressed in Chapter 6. The NHA also addresses the relationship between public and private health establishment in Section 45: "(i) The Minister must prescribe the mechanisms to enable a cocoordinated relationship between private and public health establishments in the delivery of health services. (ii) The national department, any provincial department or any municipality may enter into an agreement with any private practitioner, health establishment or non governmental organizations (NGO) in order to achieve any object of this Act."

In addition to the mentioned regulations of the NHA, Chapter 2 of the MHCA clarifies the responsibility of the State with regards to the establishment and maintenance of mental health infrastructure. For example, Section 4 states: "Every organ of the State responsible for health services must determine and coordinate the implementation of its policies and measures in a manner that - ensures the provision of mental health care, treatment and rehabilitation services at primary, secondary and tertiary levels and health establishments; promotes the provision of community-based care, treatment and rehabilitation services; promotes the rights and interests of mental health care users; and promotes and improves the mental health status of the population. "Section 3 of the MHCA however incorporates the concept of available resources in the equation: "To regulate mental health care in a manner that (a) makes the best possible mental health care, treatment and rehabilitation available equitably, efficiently and in the best interest of users within limits of available resources; (b) provides access to care treatment and rehabilitation to voluntary, assisted, involuntary users, state patients and mentally ill prisoners and (c) clarifies rights and obligations." The State according to the MHCA is thus responsible for the promotion and provision of community-based mental health care, treatment and rehabilitation while also responsible for the designation and operation of health establishments such as psychiatric hospitals, care and rehabilitation centers and 72hour assessment units. Functions of psychiatric hospitals and assessment units include multi-tiered parallel programs such as voluntary, assisted and involuntary mental health care, care of state patients, care of mentally ill prisoners, assessment of persons referred by court for psychiatric observation in terms of the Criminal Procedure Act, No. 51 of 1977 and care of persons admitted for long-term care, treatment and rehabilitation.

(iv) Clinical responsibility - The clinical responsibility of mental health care practitioners including psychiatrists is covered in Chapters 5, 6 and 7 of the MHCA. These chapters regulate the different categories of users, including "voluntary", "assisted", "involuntary", "state patients" and "mental ill prisoners". While these chapters clarify the procedures around these categories, it is clear that the mental health practitioners' responsibility specifically revolves around the clinical assessment of users, for example Section 27(4)(a)(b), 27(5) and 27(6), Section 30 (1)(2)(3) and Section 33(4)(5)(6). The basic elements in the professional responsibility of the assessing clinician are to determine if users have the capacity to make an informed decision about their mental health care, if they are refusing treatment or admission and what potential risk exists to harm self, others or property. While clinicians are responsible for the assessment and treatment of service users according to the MHCA, they are not responsible to establish and maintain adequate facilities and staffing ratios within the mental health care system. Although sub-standard physical and administrative infrastructure and poor staffing of the care system have a profound impact on the quality, context and standard of clinical service delivery and decision-making, clinicians can only provide their clinical services within the setting made available by the government as regulated. It is therefore of importance to dissect the mental health care practitioner's clinical role and responsibility to assess, diagnose and treat service users from the State's responsibility to provide and maintain an adequate system of care.

\section{Professional framework}

Challenges exist in terms of the clinical assessment of the different categories of mental health care users. For example appropriate criteria for judging a user's capacity to make an informed decision about his/her health care may include the ability: to understand information relevant to decisions; to appreciate its significance; to reason using relevant information; and to choose and express one's choice. ${ }^{3}$ Capacity in this sense may therefore also be compromised due to limitations such as language, culture and literacy, consultation time available, responsibility allocated to give and explain information and age. Age (all users younger than 18 years according to MHCA) also currently renders a user "assisted" without the (legal) capacity to make an informed decision about his/her mental health care. Yet at the same time, other legislation such as the Choice on Termination of Pregnancy Act, 
No. 92 of 1996 and the Child Care Act, No. 74 of 1983 differs with regard to the consenting age required.

Assessment of the potential risk of harm to self, others or property is another area that is difficult to assess. No clinical assessment can provide a final measure of the outcome of a person's level of aggression, propensity for violence, or risk of harm to self or others. Assessing clinicians can at best, take previous and present experiences into account to project the likelihood of possible future aggressive behavior under similar conditions. ${ }^{4,5}$ While adequate pharmacological and behavioral treatments may reduce some aspects of the risk associated with this scenario, violent behavior often depends on external environmental or situational variables, which are difficult to control or to predict.

While mental health practitioners are thus responsible for the professional clinical assessment and treatment of mental health care users, the State according to the MHCA, is accountable for the provision and maintenance of infrastructure, the financial and human resources for service delivery and for the setting and upholding of adequate norms and standards for service rendering. In view of the previous arguments, accountability of clinical staff according to the MHCA can only be interpreted to consist of the accountability for good clinical practice. In the context of possible liability, these separate responsibilities and capacities of individual practitioners versus the State will have to be taken into account in order to avoid the inappropriate allocation of accountability or blame.

The recently established mental health review boards (MHRB) have the responsibility to ensure that mental health care practitioners follow the correct procedures with regard to the admission and discharge of service users. Although these Boards review procedural matters, they have however contrary to initial expectation - no jurisdiction to rule on conditions in facilities or other service related matters. According to Chapter 4 of the MHCA, a board must consist of a minimum of three people and a maximum of five including at least one mental health care practitioner, one legal practitioner and one community member. Functions of MHRB's include the approval or rejection of initial assisted and involuntary admissions, approval or rejection of ongoing assisted or involuntary admission (more frequent periodical reports), responding to appeals, considering the transfer of users to maximum-security facilities and considering periodic reports of mentally ill prisoners. Boards are intended to be independent and supervisory, advising the political office of the provincial minister, as well as the High Court, heads of health establishments, clinicians, applicants and users on its decisions. The mental health care practitioner's role as member of the MHRB represents at least another tier of clinical accountability towards service users in the community and should contribute to the integrity and standing of these boards by the professional review of the quality and correctness of the assessment and management of users.

To identify the principle or incentive that may motivate national and provincial state health departments to actively take up their responsibility to establish infrastructure for mental health care services, to adequately prioritize and to make resources available in a transparent and accountable way, one is led to conclude that unless the State is successfully litigated to do so, it may argue that "no resources are available" to ensure appropriate facilities and standards of care or to uphold the agreed upon human rights of users. It is in this context that it seems that legal practitioners and the legal system and not the MHRB's complete the group of role players on the current South African mental health care stage. They have, by implication, been entrusted with a crucial function to uphold service users', practitioners' and service providers' rights and responsibilities. However very few legal practitioners currently appear to have experience or an interest in mental health as a specialty area. At the same time, very few users of state facilities or their families have the financial means to pursue litigation in the event of human rights and other abuses. A ruling during March 2005 of the Pretoria High Court demonstrated this issue, where the State was instructed by means of a High Court order to honor its own obligation to provide certain services to mentally ill children at Sterkfontein Hospital. This precedent further established the notion that the current mental health legislation only allows for a negative incentive such as eventual litigation to take up responsibility for providing infrastructure and staffing.

\section{Labour framework}

As workers the general framework of employment conditions in which state employed practitioners currently operate, is mainly regulated by the generic Basic Conditions of Employment Act, No. 75 of 1997 and the Labour Relations Act, No 66 of 1995. Although the State as employer is generally held responsible for the conduct of mental health practitioners in its service, no particular provision is currently made for the higher risks that state employed mental health care practitioners may be exposed to in the case of inadequate facilities and poor staffing. No additional arrangements exist with regard to insurance and compensation and it is not clear how the impact of substandard facilities and staff ratios will be taken into account in the event of any adverse incidents that may happen as a result of poor infrastructure and staffing. Clarity is still necessary within the context of the Labour Relations Act, as to clinicians' liability in their personal capacity and their protection as employees. On the issue of over-extended responsibilities of clinicians in the current reality of inadequate facilities and insufficient mental health care resources, a situation of vicarious liability may exist, where either a commissioner of arbitration may have to rule on what fair labour practice may be or alternatively, court action may be necessary to obtain a declaratory order to give guidance with regard to the respective clinical and service provision responsibilities.

\section{Discussion}

The three main pieces of legislation considered in this paper redefine the role and scope of clinical workers in health and mental health care and include for the first time a legal definition of traditional health practice. Human rights are now also addressed in legislation in the area of health and mental health, while it continues to play an important part in day-to-day clinical practice and decisionmaking. Access to health and mental health care and procedures for the adequate management of mental illness is extensively covered by the NHA and the MHCA, which allocate responsibility to provide and maintain health care systems and infrastructure to the State while expecting professional and ethical clinical practice from mental health practitioners. However, if Section 3 of the MHCA is quoted indiscriminately in the deliberation of whether resources are available or not, the conclusion must inevitably follow that human 
rights will always be subject to the alleged non-availability of resources. The link created between these concepts by the MHCA makes it imperative to be able to assess if and what resources are available in the first place. It will also require a very transparent process in order to ascertain if adequate resources were made available within given restraints and that resources are actually utilized in a way that upholds the human rights of users to have adequate access to services and treatment. No such process currently exists in the South African health system and although the principle can be regarded as formally legislated, no financial assessment or alignment with $\mathrm{MHCA}$ requirements of national or provincial budgets to evaluate the availability of mental health resources has yet been formally undertaken.

While the protection of mental health users' human rights is fully supported by clinicians, without the necessary alignment of State facilities and available resources with the requirements of the Act, it will not be possible to implement this legislation. Although the MHCA and other legislation are very clear on the State's role, no provision was made to enable its implementation. In most provinces, provision has not been made for the upgrading of existing facilities such as acute units responsible for the 72-hour observation of involuntary users in general district and regional hospitals, nor has there been an improvement in staff-to-patient ratios. Due to the current limited resources however, practitioners often work in an environment where staff ratios are a fraction of what they should be and in units with completely inadequate security systems. Apart from posing significant risks for staff working under these circumstances, the legal and ethical aspects of where responsibility for patient care rests are not directly addressed. It is not clear to what extent the State or individuals working within inadequate, insecure public mental health environments are responsible for abuses or incidents of human rights violations that may occur. These incidents are often largely due to inadequate staffing and structure of hospitals.

\section{Conclusion}

Within this current new framework for mental health care delivery in South Africa, the following suggestions can be made: (1) Resources available for mental health in South Africa should be routinely aligned with Chapter 3 of the MHCA in a transparent way to ensure the human rights of mental health care users, e.g equipped 72-hour assessment units, adequate child and adolescent services, community facilities such as day care centers; (2) Norms and standards should be set for the public sector as for the private sector in order to align the state infrastructure with the new legislation, while ways must be found to integrate private practitioners in the current referral system where appropriate, to reduce the number of private assisted or involuntary users managed in state facilities; (3) As their private counterparts did to negotiate an acceptable fee structure, state employed psychiatrists must play a more organized role as advocates to uphold the human rights of mental health users to have access to adequate public services and treatment, as well as for market related remuneration for state employed clinicians (see Addendum); (4) The legal, professional and labour framework of state employed mental health practitioners as workers must be further clarified and strengthened with assistance from legal advisers where necessary and through their affiliations such as the SA Society of Psychiatrists and SA Medical Association; (5) Apart from personal malpractice insurance and payments of law suits from the particular hospitals' allocated budgets, adequate professional insurance by the State for its hospitals and state employed clinicians must be secured especially where incidents may be related to inadequate facilities or staffing; and (6) Despite the significant part that mental health seems to have been allocated in the definition of traditional health practice, any possible future extension of the multi-disciplinary team for example to include traditional health or other alternative practitioners, must in view of the current poor prioritisation of mental health and the prevailing strain on available resources at this point in time, only be considered with reservation.

\section{References}

1. Department of Health, South African. Retrieved October 17, 2006; from hhtp://www.doh.gov.za/docs/top.html

2. White Paper for the Transformation of the Health System in SA, Government Gazette No. 17910 of 16 April 1997

3. Messer NG. Professional-patient relationships and informed consent. Postgrad Med J 2004; vol 80, pp 277-283.

4. Simon RI. Ethics and Forensic Psychiatry. In: Sadock BJ and Sadock VA (ed.), Kaplan and Sadock's Comprehensive Textbook of Psychiatry Volume 2. Seventh Edition. Lippencott, Williams and Wilkens, Philadelphia, 2000; pp 3272 -3300.

5. Kaliski SZ. Risk Assessment and Management and the New Mental Health Care Act. Paper presented at the 1st Regional CINP Meeting, Cape Town, 20-22 April 2005.

\section{ADDENDUM: PROPOSED POSITION STATEMENTS OF THE SA SOCIETY OF PSYCHIATRISTS' (SASOP) STATE EM- PLOYEE SPECIAL INTEREST GROUP (SESIG) ON PUBLIC MENTAL HEALTH CARE PRACTICE IN SA}

1. THE RESPONSIBILITY OF THE STATE TO PROVIDE MENTAL HEALTH CARE INFRASTRUCTURE

IT IS ESSENTIAL THAT PUBLIC SECTOR MENTAL HEALTH PRACTITIONERS ARE PROTECTED FROM A MEDICO-LEGAL, PROFES-

SIONAL AND LABOUR POINT OF VIEW. MENTAL HEALTH PRACTITIONERS' CLINICAL JUDGEMENT, DECISIONS AND PRACTICE MAY BE COMPROMISED AS A RESULT OF SUBSTANDARD INFRASTRACTURE AND POOR STAFFING CONDITIONS. WE NEED TO BE GUARENTEED OF ADEQUATE, SAFE WORKING CONDITIONS FOR OUR PATIENTS AND FOR OURSELVES.

2. CURRENT CONDITIONS OF SERVICE IN THE PUBLIC SECTOR IN ORDER TO PROTECT AND STRENGTHEN ACADEMIC AND SPECIALIST PSYCHIATRIC CARE IN SOUTH AFRICA, THERE NEEDS TO BE AN URGENT RECONSTRUCTION OF THE STRUCTURE, CONDITIONS OF SERVICE, REMUNERATION AND CAREER PATHS FOR JOINT EMPLOYED ACADEMIC AND STATE EMPLOYED SERVICE DELIVERY SPECIALISTS.

3. THE MANAGEMENT OF CARE PROGRAMS IT SHOULD BE ACKNOWLEDGED THAT JOINT AND STATE EMPLOYED PSYCHIATRISTS SHOULD PLAY A CENTRAL ROLE IN THE STRATEGIC AND OPERATIONAL PLANNING OF MENTAL HEALTH SERVICES AT A PROVINCIAL AND NATIONAL LEVEL. SPECIFIC TIME FRAMES, DEFINITIONS OF CARE AT DIFFERENT LEVELS, NORMS AND STANDARDS OF CARE, RESOURCES TO BE ALLOCATED AND THE ROUTINE MONITORING/AUDITING OF MENTAL HEALTH CARE PROGRAMS NEEDS TO BE DONE IN CONJUNCTION WITH STATE EMPLOYED PSYCHIATRISTS.

Drafted by ABR Janse van Rensburg SASOP SOUTHERN

GAUTENG SESIG Representative

Submitted to National SESIG Representatives

At 14TH NATIONAL SASOP CONGRESS

SWAZILAND, 12 September 2006 